\title{
Effects of an Oscillating Flap on the Main Airfoil Unsteady Lift in Grid Turbulence
}

Stapountzis, Herricos; Barlas, Athanasios; Papageorgiou, Georgios; Patsiouras, Athanasios

Publication date:

2018

Document Version

Publisher's PDF, also known as Version of record

Link back to DTU Orbit

Citation (APA):

Stapountzis, H., Barlas, A., Papageorgiou, G., \& Patsiouras, A. (2018). Effects of an Oscillating Flap on the Main Airfoil Unsteady Lift in Grid Turbulence. Paper presented at IUTAM Symposium 2018, Santorini, Greece.

\section{General rights}

Copyright and moral rights for the publications made accessible in the public portal are retained by the authors and/or other copyright owners and it is a condition of accessing publications that users recognise and abide by the legal requirements associated with these rights.

- Users may download and print one copy of any publication from the public portal for the purpose of private study or research.

- You may not further distribute the material or use it for any profit-making activity or commercial gain

- You may freely distribute the URL identifying the publication in the public portal 


\title{
Effects of an Oscillating Flap on the Main Airfoil Unsteady Lift in Grid Turbulence
}

\author{
Herricos STAPOUNTZIS*, Athanasios BARLAS**, Georgios \\ PAPAGEORGIOU*, Athanasios PATSIOURAS* \\ *University of Thessaly, Dept of Mechanical Engineering, Volos 383 34, Greece. **DTU, 4000 Roskilde, \\ Denmark. erikos@uth.gr
}

\begin{abstract}
A wing of NACA 0015 profile and Aspect Ratio 2.4 fitted with a Trailing Edge Flap was tested in a wind tunnel for both smooth and turbulent flow conditions at a Re number 108000. The unsteady lift on the wing was measured with and without the flap. Two types of flap excitation were tried: One was of the "open loop" type in which the flap was subjected to sinusoidal pitching oscillations while the wing was set to a constant angle of attack. In the second, "closed loop" mode, the excitation signal fed into the flap originated from the unsteady lift of the wing itself. The phase lag between those signals was changed and it was found that it played a significant role in the suppression of the main wing unsteady lift.
\end{abstract}

Key words: trailing edge flap, wind turbine load alleviation, smart blades, unsteady aerodynamics, active flow control.

\section{Introduction}

Atmospheric turbulence and gusts are responsible for inducing unsteady loads to airplane wings, helicopter blades and wind turbine rotors. The last ones however, on account of their relatively larger size, are subjected to additional cyclic load increments due yaw misalignment, tower shadow and wind shear in the atmospheric boundary layer. Flapwise bending moments near the blade root would be a serious cause for fatigue. It is desirable to maintain, as much as possible, a rather steady or prescribed blade loading in order to lower the fatigue risk and also suppress vibrations especially for helicopter blades. Various methods have been tried towards this objective, which in some cases could also result in increased annual energy production of the wind turbine, Barlas et [1], Krzysiak et al [2], Siala et al [3], Maldonaldo et al [4]. Collective or individual pitching of the wind turbine blades (cyclic pitch with a phase shift) was found to effectively reduce fatigue loads, Larsen et al [5], but rather sluggish to attenuate atmospheric turbulence effects. Better control of the blade lift would be accomplished by moving a large hinged flap through a small angle, Hassan et al [6]. Further load reductions could be effected by the deployment of small size trailing edge flaps, or deformable, "morphing" trailing edges, which because of their smaller moment of inertia, would be accordingly activated to account for various unsteady conditions, including shorter atmospheric gusts, Teun et al [7], Wolff et al [8], Madsen et al [9], Pankonien et al [10], Valasek [11]. Considerable research is devoted to such "smart rotor" innovations from both the experimental and 
computational point of view. One issue is the correct and realistic aerodynamic modelling and another one is the method of active control (open or closed loop), Bergami et al [12], Frederick et al [13]. With regard to aerodynamic problems, among the points of interest are the size and position of the flap relatively to the main wing, the amplitude of deflection $\beta_{0}$ and the pitch rate, in case the wing is at a steady angle of attack $\alpha$. If the wing itself oscillates along with the flap then their phase difference needs to be investigated. It was found that there exist regimes of appropriate phase difference where the undesirable unsteady lift is suppressed, Bak et al [14], Bergami et al [15], Krzysiak et al [2], Wolff et al [8].

Figure 1, adapted from the experimental results of [14], shows how the fluctuating part of the unsteady lift on the main steady fixed wing at $\alpha=4.6^{0}$ is influenced by the reduced frequency $\mathrm{k}$ of sinusoidal flap oscillation during a full cycle. The reduced frequency is defined as $\mathrm{k}=\omega \mathrm{c} /\left(2 \mathrm{U}_{\infty}\right)$, where $\omega$ is the circular frequency of oscillation $\omega=2 \pi \mathrm{f}, \mathrm{f}$ being the frequency in $\mathrm{Hz}, \mathrm{c}$ is the wing chord, including the flap chord and $\mathrm{U}_{\infty}$ is the free stream speed. The instantaneous flap angle is $\beta$ (in degrees) and half amplitude of the flap oscillation is denoted by the angle $\beta_{0}$.

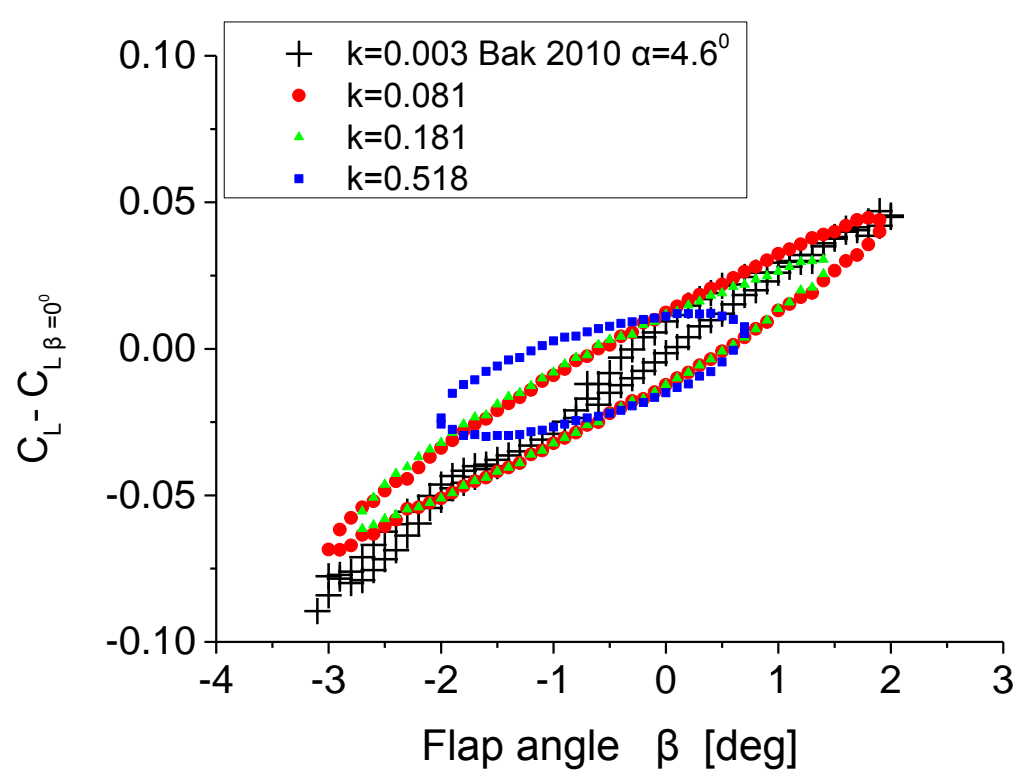

Figure 1. Fluctuating part of the lift with flap angle $\beta$ in sinusoidal oscillation and main wing RISOE B1-18 steady at angle of attack $\alpha=4.6^{0}$. Adapted from wind tunnel test results of Bak et al 2010, [14].

For sinusoidal motion the root mean square of $\beta, \beta_{\mathrm{RMS}}=\beta_{0} / \sqrt{2}$. Due to experimental limitations the amplitude $\beta_{0}$ could be maintained at a constant level as the frequency of oscillation was varied, a problem that was encountered in the experiments of the present work, as will be seen later. It is observed that the unsteady lift amplitude and consequently its RMS value decrease with reduced frequency as well as the average lift curve slope. The loop in the $C_{L}-\beta$ curve, as 
reported in [14], is counterclockwise indicating a favorable behavior towards the lowering of the unsteady lift.

Figure 2, shows similar results from the computational work of Bergami et al [15], using their ATEF (Adaptive Trailing Edge Flap) engineering model. The main wing is set at a zero angle of attack $\alpha=0^{0}$.

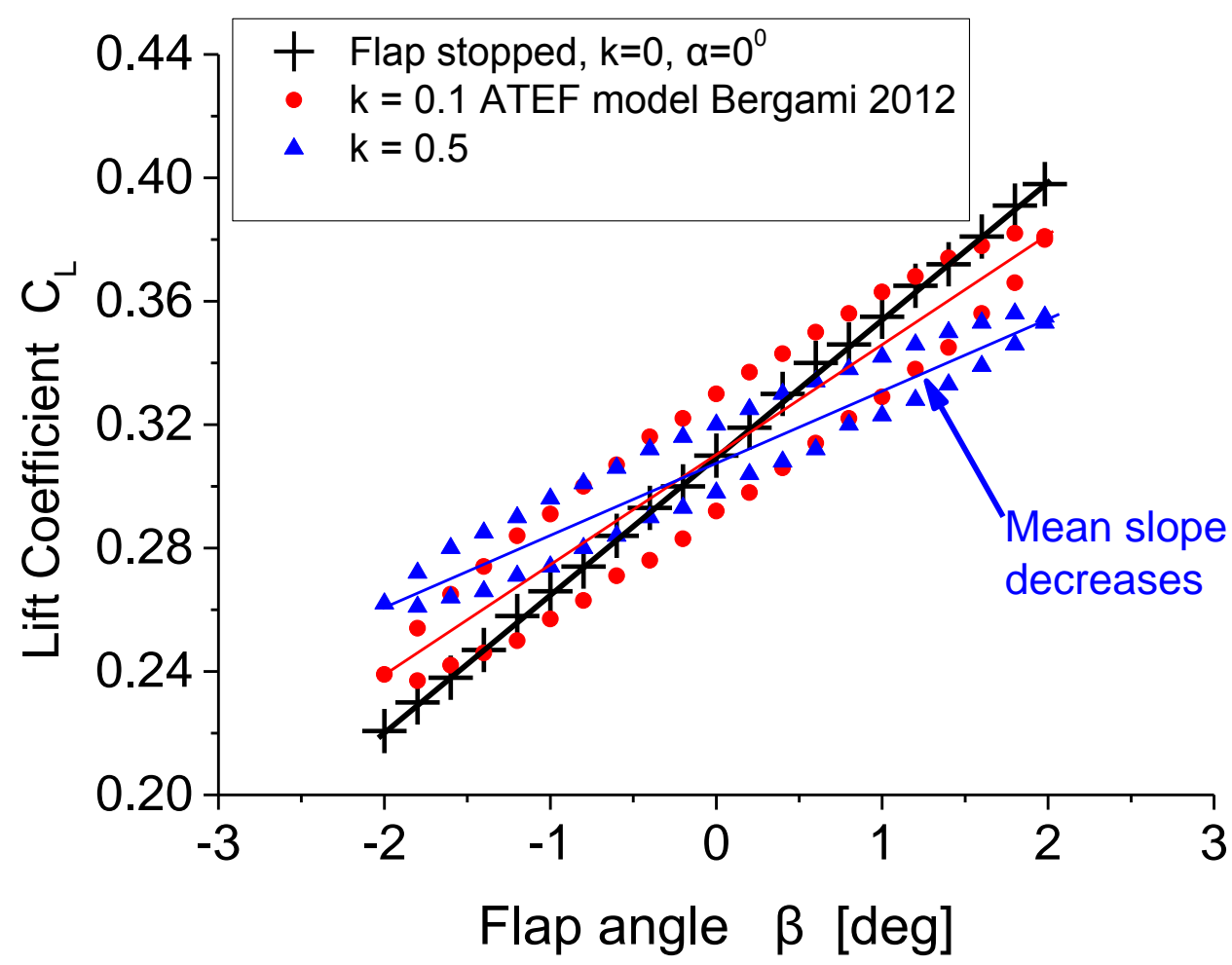

Figure 2. Unsteady Lift Coefficient for various oscillating flap reduced frequencies with wing NACA 64-418 steady at $\alpha=0^{0}$. Adapted from ATEF model calculation results of Bergami et al 2012, [15].

The computations show that when the amplitude of flap oscillation $\beta_{0}$ was set to $\beta_{0}=2^{0}$ there is a systematic trend to reduce the unsteady lift as $\mathrm{k}$ increases.

Figure 3, adapted from [14], shows the experimental results for combined sinusoidal motion of the wing and its attached flap. A phase difference of $40^{\circ}$ yields the lowest unsteady lift fluctuation. On the other hand, inappropriate phase differences may increase the unsteady lift significantly, e.g. $\Delta \varphi=-150^{\circ}$.

In the present work experiments of similar nature to those reported from [14] above are carried out in order to examine the influence of reduced frequency, turbulence intensity and manner of flap excitation on the wing unsteady lift. Comparisons with the experimental findings of [14] and [15], where possible, due to the big difference in the wing chord to flap chord ratios, will be attempted. 


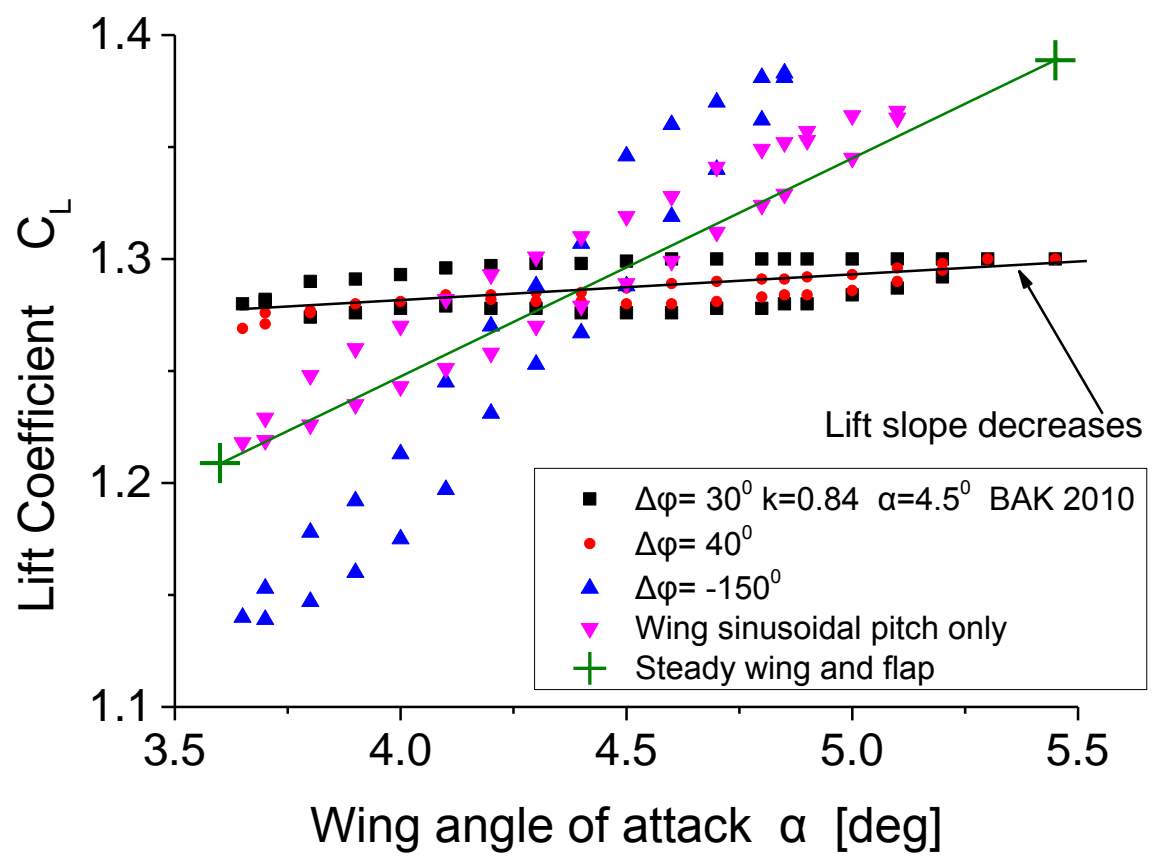

Figure 3. Unsteady Lift Coefficient for simultaneous wing and flap sinusoidal oscillation at $\mathrm{k}=$ 0.84 and main wing RISOE B1-18 angle of attack $\alpha=4.5^{\circ}$. The phase difference between wing and flap is $\Delta \varphi$ degrees. Adapted from wind tunnel test results of Bak et al 2010, [14].

\section{Experimental Setup}

The open, suction type wind tunnel at the University of Thessaly Mechanical Engineering Department was employed for the unsteady lift measurements using piezoelectric force transducers. The wind speed was $U_{\infty}=13 \mathrm{~m} / \mathrm{s}$ and the 2-D wing / flap assembly of $\mathrm{AR}=2.4$ with end plates was positioned $20 \mathrm{M}$ downstream of a standard biplanar grid $(\mathrm{M}=90 \mathrm{~mm}$ mesh to square bar size ratio $=4.5)$. At this downstream location the turbulence intensity without the grid was $0.7 \%$ and with the grid $5 \%$.

The wing was of the NACA 0015 profile with chord $\mathrm{c}=125 \mathrm{~mm}$ and the flap profile was close to that of an EPPLER $56117 \%$ thick profile of chord length $\mathrm{c}_{\mathrm{F}}=$ $65 \mathrm{~mm}$, Figure 4 . Tests were performed at Reynolds numbers $\mathrm{Re}=\mathrm{U}_{\infty} \mathrm{c} / \nu$ between 108000 and 135000. The wing chord to flap chord ratio $\mathrm{c} / \mathrm{c}_{\mathrm{F}}$ in this work is equal to 1.92, which is in fact too small compared to the ratio found in the literature, [14]. Limitations in the Lab instrumentation has contributed to this decision.

Two types of flap rotary oscillation were considered (mechanically accomplished by means of a hinge and a connecting rod mounted on a powerful loudspeaker): a) sinusoidal, of frequency $\mathrm{f}_{\mathrm{F}}$, by means of an independent signal generator of which the amplified signal was fed into the loudspeaker and $b$ ) by feeding the unsteady (turbulent) lift signal of the wing into the amplifier and subsequently into the loudspeaker in order to vibrate the hinged flap. The wing and the flap were mounted independently, so that mechanical cross-talk of forces would be avoided. 
For case a) the flap frequencies were equal to $0,10,12.5,15$ and $20 \mathrm{~Hz}$ with corresponding half amplitudes $\beta_{0}=0$ (no flap oscillation), $25.4^{\circ}, 6.6^{\circ}, 3.1^{\circ}$ and $2^{0}$. For case $b$ ) the unsteady lift signal was fed into the loudspeaker via two different ways: first, directly from the output of the amplifier and second, with its polarity reversed. In the former case, the unsteady lift and the excitation were in phase (denoted as "Phase Lift") while in the latter they were $180^{\circ}$ out of phase ("180 Lift"). The shape of the two time records was checked visually using an oscilloscope and also numerically via the coherence function of the corresponding analogue signals, simultaneously sampled in time.

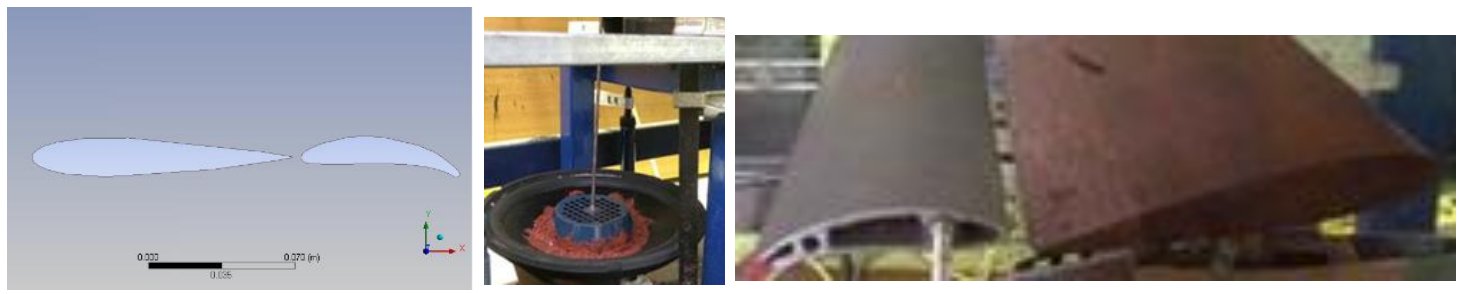

Figure 4. Wind tunnel models. Main wing NACA 0015, chord $\mathrm{c}=125 \mathrm{~mm}$, span $\mathrm{b}=300 \mathrm{~mm}$. Flap EPPLER $56117 \%$ thick, chord $\mathrm{c}_{\mathrm{F}}=65 \mathrm{~mm}$, span $=300$. Reduced frequency $\mathrm{k}$ is based on $\mathrm{c}$.

\section{Unsteady Lift results for the Model Wing without a Flap}

Figure 5 presents experimental data for the unsteady lift on an isolated nonoscillating wing (no flap) set at a steady angle of attack $\alpha$. Variability in the unsteady lift may arise from the inherent flow unsteadiness of a wind tunnel in nominally "smooth" flow (for example acoustic excitation) or background turbulence, intentionally generated turbulence, as in this work by means of a grid, turbulent boundary layer on the wing surface, flow separation (stall) and to some extend extraneous noise from the force balance.

The root mean square of the fluctuating part of the unsteady lift coefficient, $\mathrm{C}_{\mathrm{L}}$ RMS , which is plotted against $\alpha$, is seen to increase with angle of attack in all cases, concerning our results and those found in the literature, e.g. Gaunaa [16], Smith et al [17], Humphreys [18], Lysak et al [19].

Our results show that grid turbulence with an intensity $\mathrm{i}$ of $5 \%$ causes significant increase in the $\mathrm{C}_{\mathrm{L} \text { RMS }}$ of the NACA 0015 wing, compared to that in the wind tunnel flow without the grid $(i=0.7 \%)$. The data of Gaunaa [16] suggest lowering of $\mathrm{C}_{\mathrm{L} R \mathrm{R} S}$ as Re increases, partly because of the lower turbulence intensities at higher wind speeds.

As stall is approached the unsteady lift increases $\left(\alpha>15^{0}\right)$ in all data. Closer to our results are those of Smith et al [17], who tested a NACA 0012 wing in the turbulent boundary layer of a water tunnel and those of Lysak et al [19] (not shown in Figure 5) who measured the unsteady lift on a NACA $65_{1 \mathrm{~A}}-012$ wing in a water tunnel with grid turbulence. Their data point to a ratio $\mathrm{C}_{\mathrm{L} \text { RMS-TURB }} / \mathrm{C}_{\mathrm{L} \text { RMS- }}$ 


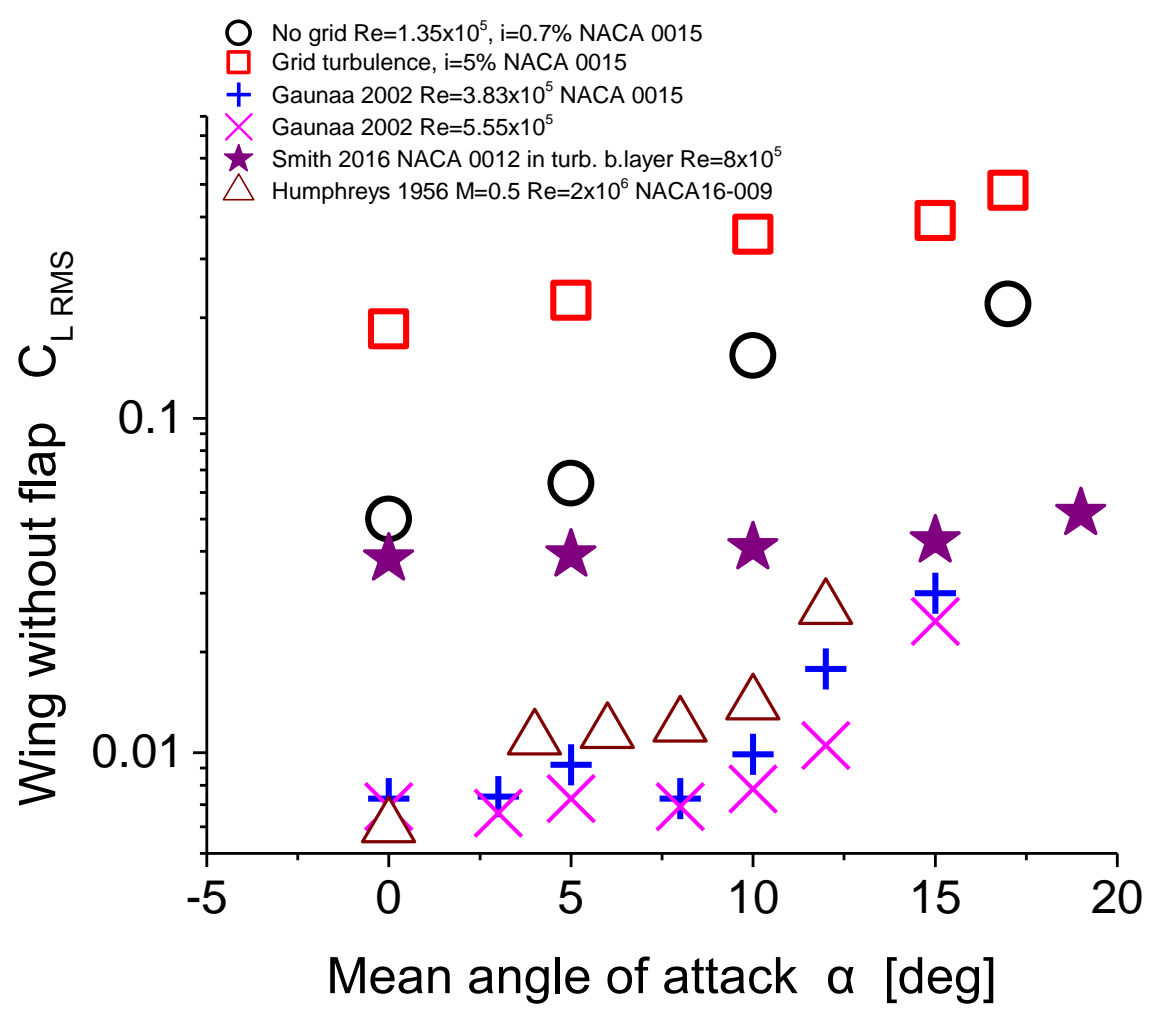

Figure 5. Fluctuating lift for wings without flap in smooth and turbulent flows from present experimental work and from Gaunaa et al [16], Smith et al [17 ], Humphreys [18].

Sмоотн $=3.2$ for $\alpha=0^{0}$, of the same order of magnitude found by Stapountzis [20] in earlier experiments in a wind tunnel. Increase in airfoil thickness is also known to cause higher unsteady lift.

\section{Unsteady Lift with Flap in Steady Conditions}

This section deals with the unsteady lift of the wing equipped with the flap, but not yet in oscillation, $\beta=0^{0}$. Values of $C_{L}$ RMS are again plotted against $\alpha$ for smooth flow and grid turbulence in Figure 6.

The presence of the flap and for angle of attack $\alpha=0^{0}$, increases the unsteady lift in smooth flow by about $50 \%$, while it has the opposite effect in turbulent flow, the unsteady lift decreases by about $15 \%$. At $\alpha=7.5^{\circ}$ and turbulent flow, no appreciable change in the unsteady lift is noticed due to the flap presence (compare Figures 5 and 6).

Bak et al [14] measured the unsteady lift on a Risoe-B1-18 airfoil with $\mathrm{c} / \mathrm{c}_{\mathrm{F}}=10$, at quasi steady conditions $(\mathrm{k} \approx 0.003)$ at $\mathrm{Re}=1.66 \times 10^{6}$ and background wind tunnel turbulence $\approx 1 \%$. The $\mathrm{C}_{\mathrm{L} \text { RMS }}$ at $\alpha=4.6^{0}$ was 0.04 , close to our result for smooth flow at $\alpha=0^{0}$. It seems therefore that grid turbulence attenuates the interference caused by the flap in a steady condition $\left(\beta=0^{0}\right)$ with regard to the unsteady lift development. 


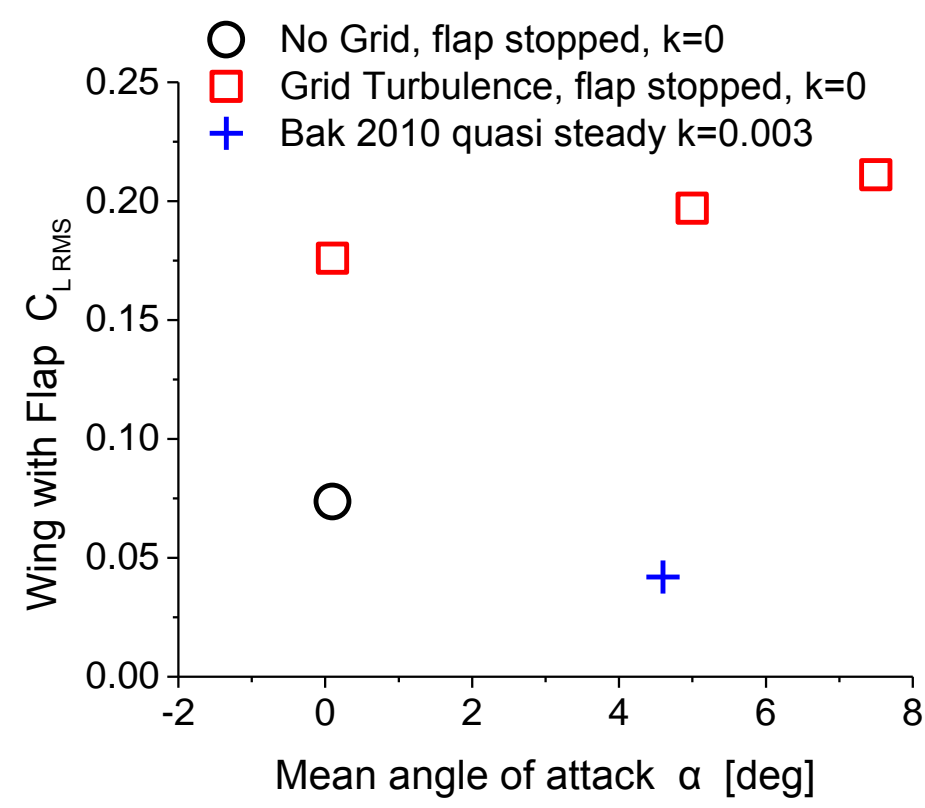

Figure 6. Fluctuating lift for wings with flap in smooth and turbulent flows from present experimental work with flap steady $\left(\mathrm{k}=0, \beta=0^{0}, \mathrm{Re}=1.08 \times 10^{5}\right)$ and from Bak et al [14], (quasisteady, $\mathrm{k} \approx 0.003, \mathrm{Re}=1.66 \times 10^{6}$ )

\section{Unsteady Lift with Flap in Sinusoidal Forcing}

Figures 7 and 8 demonstrate how the oscillating flap in sinusoidal excitation, $\beta(\mathrm{t})$ $=\beta_{0} \cos (\omega \mathrm{t})$, influences the unsteady lift of the main wing. The nearest (taking into account the too small value of $\mathrm{c} / \mathrm{c}_{\mathrm{F}}$ in the present experiments) available data for comparison are those reported in [14] (experiments, $\alpha=4.6^{\circ}$ ) and in [15] (computations with the ATEF model, $\alpha=0^{0}$ ). Representative plots of the $\beta-\mathrm{C}_{\mathrm{L}}$ lobes with increasing $\mathrm{k}$ were given in Figures 1 and 2 in the Introduction. Using their data the root mean square lift coefficients were computed. In order to bring their results to a comparable form with ours the $C_{L}$ RMS data were normalized with the RMS flap amplitude, $\beta_{0}$ RMS , assuming variations of the type $\beta(t)=\beta_{0} \cos (\omega t)$ (with $\omega=2 \pi \mathrm{f}_{\mathrm{F}}$ ).

Figure 7 shows the variation of the normalized RMS lift coefficient with reduced frequency at $\alpha=0^{0}$ for smooth and turbulent flow. Our data point to a non favorable contribution of the flap excitation for unsteady lift alleviation especially for grid turbulence. A roughly linear increase of the normalized lift with $\mathrm{k}$ is observed, one of the reasons could be the large size of the flap compared to the wing and the large unsteadiness caused in its wake. The increase in the normalized lift with reduced frequency $\mathrm{k}$ found from the data in [15] and [21] is very mild compared to ours. In their work the RMS values of the fluctuating parts of the unsteady lift for $\mathrm{k}=0.1$ and 0.5 are 0.019 and 0.027 respectively and the normalized values for $\beta_{0}=2^{0}$ are shown in Figure 7. A fair agreement might be assumed in the low reduced frequency regime, $\mathrm{k}<0.3$. 


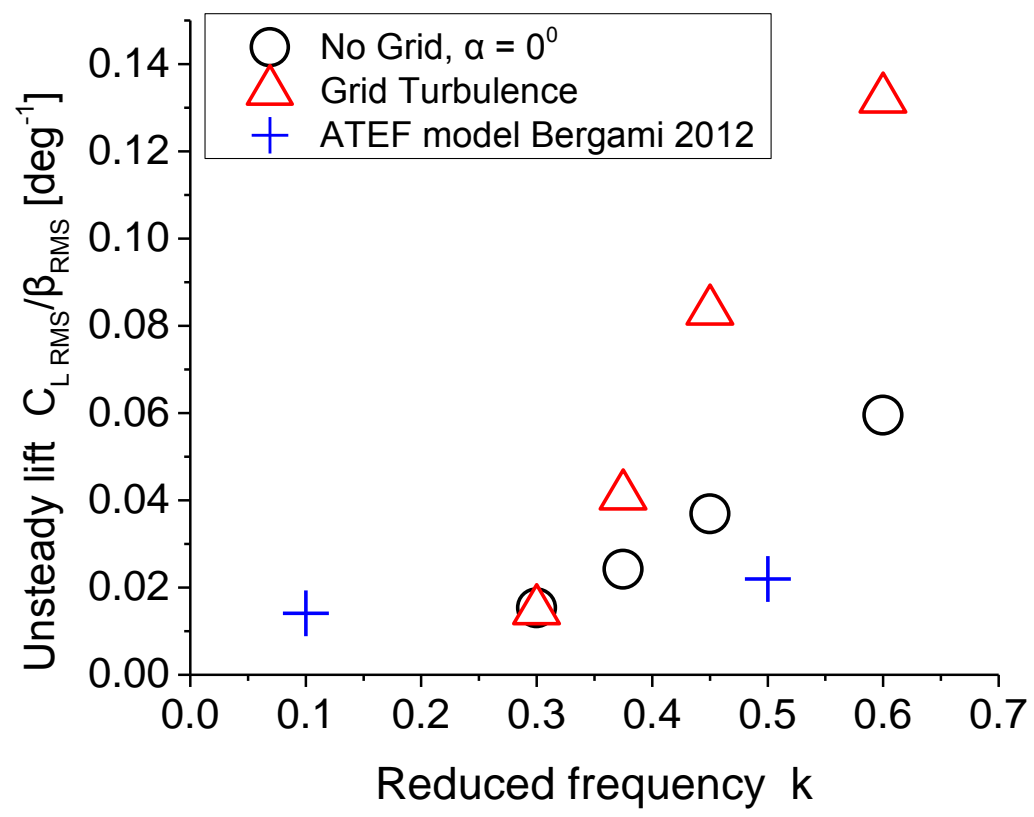

Figure 7. Normalized fluctuating lift for wings at $\alpha=0^{0}$ with flap in smooth and turbulent flows from present experimental work for flap with sinusoidal excitation and from ATEF model of Bergami et al 2012 [15]

In Figure 8 there are data for more angles of attack besides the zero angle, i.e. for $\alpha=5^{0}, 7.5^{0}$ (our experimental data) and $\alpha=4.6^{0}$ (experimental data in [14]).

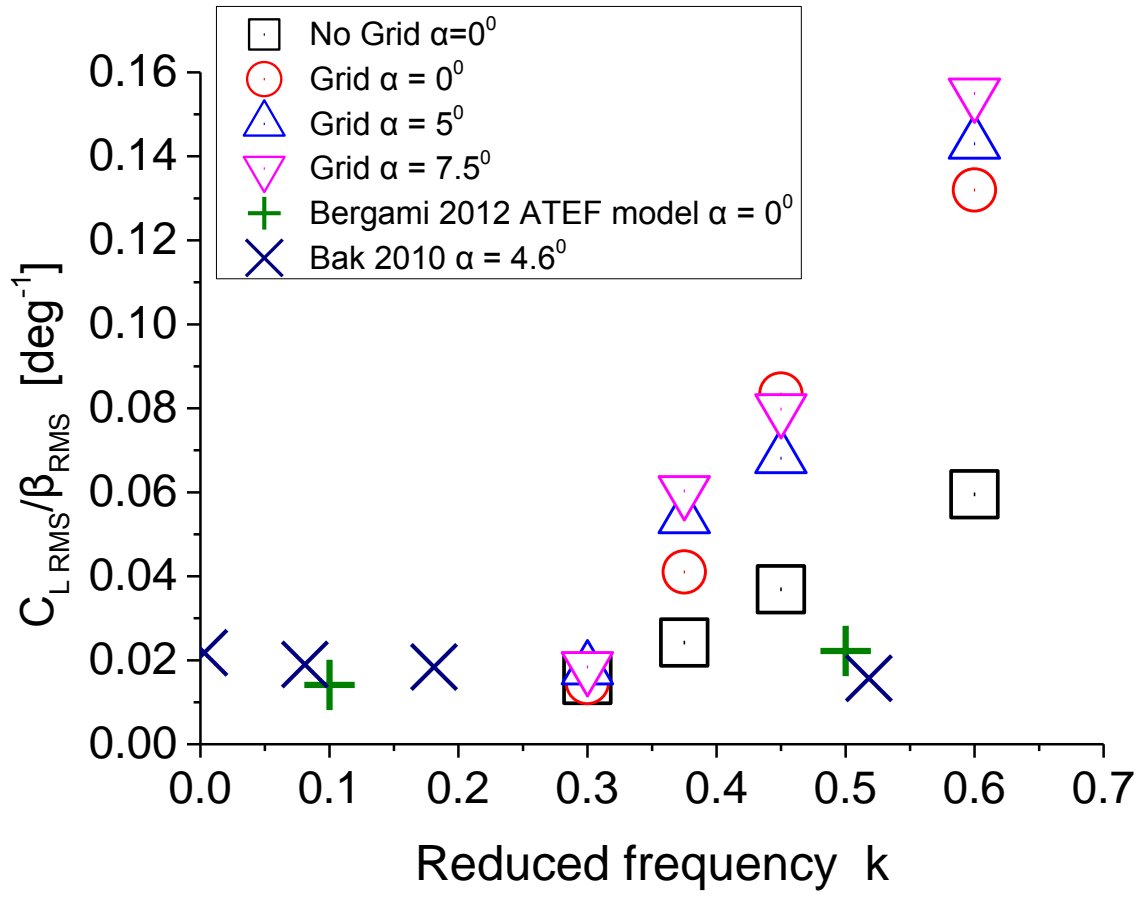

Figure 8. Effect of reduced frequency $\mathrm{k}$ and mean angle of attack $\alpha$ on the normalized fluctuating lift for wings with flap in smooth and turbulent flows from present experimental work for flap with sinusoidal excitation and from Bak et al 2010 [ 14] 
In our case the normalized lift does not seem to be significantly influenced by increases in the angle of attack at least in the range examined $\left(0^{0}\right.$ to $\left.7.5^{\circ}\right)$ and again it increases with reduced frequency $\mathrm{k}$. On the contrary, the experimental results of Bak et al [14] indicate a mild, though favorable effect of the flap oscillation on the alleviation of the unsteady lift. The data taken from Figure 1, [14], and normalized as described above show in Figure 8 that the unsteady lift can indeed be lowered when $\mathrm{k}$ increases. There are no available data beyond $\mathrm{k}=0.5$ in order to ascertain whether this favorable effect reaches an optimum value for load alleviation. Research with sinusoidal excitation dealing also with phase changes is quite extensive in this respect e.g. [22], [23].

\section{Unsteady Lift with Flap in a Closed Loop Excitation}

The signal fed to the actuator moving the flap was the unsteady lift felt by the wing in turbulent flow. It was beforehand amplified in order to be able to drive the powerful loudspeaker. The two signals were followed in time and recorded for further analysis. As mentioned in section 3, the phase between the two signals could be altered by changing the polarity in the actuator (loudspeaker). Then the flap would move in the opposite direction. The advantageous effect of a flap as a high lift device is well documented, i.e. when the flap moves downwards, $\beta<0$, (assuming that upwards causes the wing nose up, $\alpha>0$ ) the lift increases. Figure 9 shows that this phase lag can dramatically affect the normalized unsteady lift. In Figure 10 time traces of the two signals are presented.

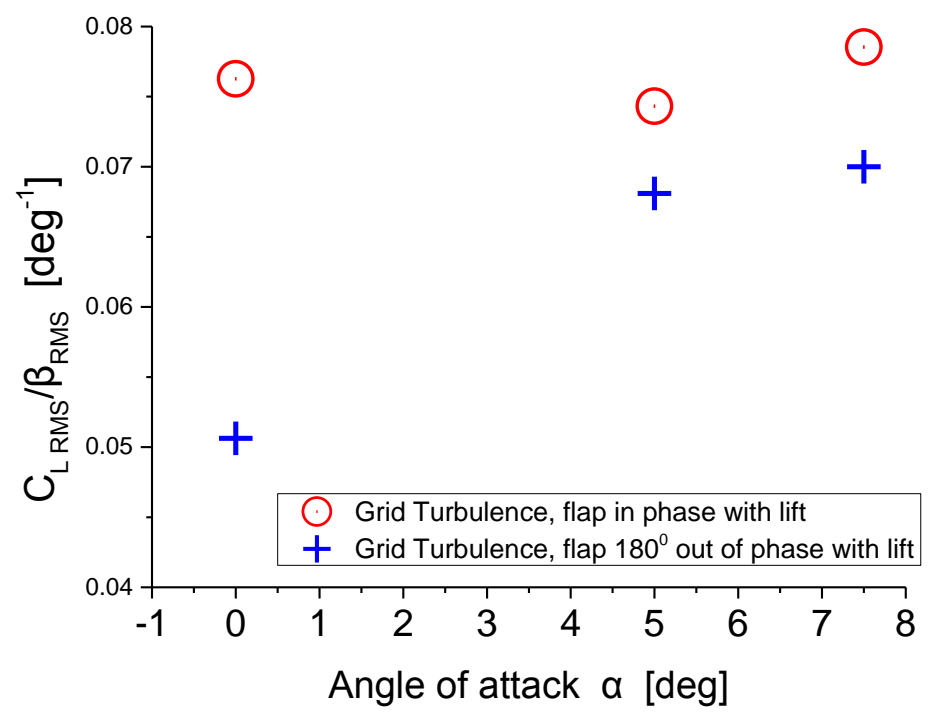

Figure 9. Effect of feedback method (lift-flap phase shift $0^{\circ}$ and $180^{\circ}$ ) and mean angle of attack $\alpha$ on the normalized fluctuating lift for wing with flap in smooth and turbulent flow.

The decrease with phase change in the normalized lift is more pronounced at low angles of attack. For example at $\alpha=0^{0}$ the lift without phase change is about 0.075 , while with $180^{\circ}$ phase change the corresponding value is 0.05 . Reverting to Figure 
8 and assuming sinusoidal excitation this would imply operation at a reduced frequencies $\mathrm{k} \approx 0.45$ and 0.35 respectively. It is as if the phase change reduces the strength of the unsteadiness of lift in terms of sinusoidal excitation. Further work would be needed in order to cover a wide range of phase differences and perhaps locate an optimum for unsteady lift alleviation.

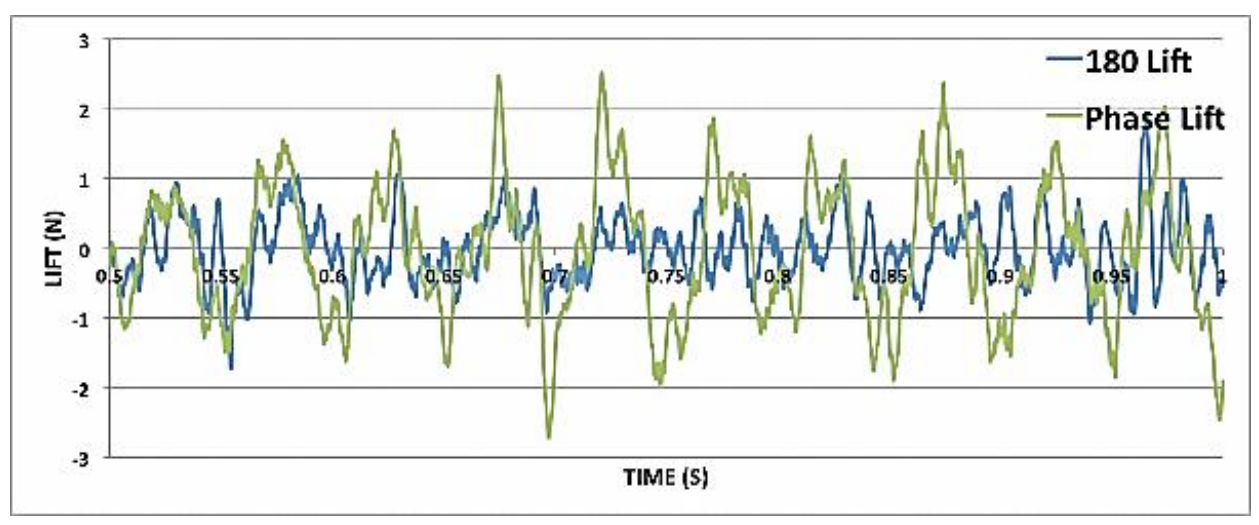

Figure 10. Unsteady lift record in turbulent flow with feedback flap excitation using the lift signal and phase shift for no phase shift $0^{\circ}$ (green) and $180^{\circ}$ (blue)

\section{Conclusions}

The experimental results of the present study show that unsteady lift is affected by trailing edge flaps but the degree of load alleviation depends on many factors like the relative size of the flap and the excitation mode. For sinusoidal excitation, the presence of strong turbulence renders the effects of changes in mild angles of attack (e.g. $\alpha<8^{0}$ ) less important than changes in the reduced frequency of oscillation. Flap excitation with a signal originating from the unsteady lift sensed by the main wing itself seems to have potential benefits for unsteady lift alleviation provided that appropriate phase differences in the closed loop procedures are used. Smart rotors and their control strategies is currently drawing a lot of attention in the wind energy scientific and industrial sector, [24], [25], [26], [27]

\section{References}

1. Barlas T.K., and Kuik van G.A.M., State of the art and prospectives of smart rotor control for wind turbines. In: The Science of Making Torque from Wind, Journal of Physics: Conference Series, 75, (2007), 012080.

2. Krzysiak A. and Narkiewicz J., Aerodynamic loads on airfoil with trailing-edge flap pitching with different frequencies. Journal of Aircraft, 43, (2), (2006), 407

3. Siala F. and Liburdy J.A., Energy harvesting of a heaving and forward pitching wing with a passively actuated trailing edge. Journal of Fluids and Structures, 57, (2015), 1-14. 
4. Maldonado V., Farnworth J., Gressick W. and Amitay M., Active control of flow separation and structural vibrations of wind turbine blades. Wind Energy., 13, (2010), 221-237.

5. Larsen T.J., Madsen H.A. and Thomsen K., Active load reduction using individual pitch, based on local blade flow measurements. Wind Energy, 8, (2005), 67-80.

6. Hassan A.A., Experimental/numerical evaluation of integral trailing edge flaps for helicopter rotor applications. Journal of the American Helicopter Society, 50, (2005), 3-17.

7. Hulskamp T., Champliaud H., Wingerden van J.-W., Barlas A., Bersee H,.Kuik van G. and Verhaegen G., Smart dynamic rotor control: Part 1, Design of a smart rotor. In: The Science of Making Torque from Wind, (2010).

8. Wolff T., Ernst B. and Seume J.R., Aerodynamic behavior of an airfoil with morphing trailing edge for wind turbine applications. In: The Science of Making Torque from Wind 2014, Journal of Physics: Conference Series, 524, (2014), 012018.

9. Madsen A.H., Andersen P.B., Andersen L.T, Bak C., Buhl T. and Li N., The potentials of the controllable rubber trailing edge flap (CRTEF). In: EWEC Proceedings (2010).

10. Pankonien A. and Inman D.J., Experimental testing of spanwise morphing trailing edge concept. In: Proc. of SPIE, 8688, (15), (2013), 1-13.

11. Valasek J. (Ed.), Morphing aerospace vehicles and structures. Publisher John Wiley \& Sons Ltd, (2012).

12. Bergami L. and Hansen M.H., High-fidelity linear time-invariant model of a smart rotor with adaptive trailing edge flaps. Wind Energy, 20 (3), (2017), 431-447.

13. Frederick M., Kerrigan E.C. and Graham J.M.R., Gust alleviation using rapidly deployed trailing-edge flaps. J. Wind Eng. Ind. Aerodyn., 98, (2010), 712-723.

14. Bak C., Gaunaa M., Andersen P.B., Buhl T., Hansen P. and Clemmensen K., Wind tunnel test on airfoil Riso-B1-18 with an active trailing edge flap. Wind Energ., 13, (2010), 207219.

15. Bergami L., Riziotis V.A. and Gauna M., Aerodynamic response of an airfoil section undergoing pitch motion and trailing edge flap deflection: a comparison of simulation methods. Wind Energy., 18, (7), (2015), 1273-1290.

16. Gaunaa M., Unsteady aerodynamic forces on NACA 0015 airfoil in harmonic translator motion. PhD Thesis, Technical University of Denmark, (2002).

17. Smith S.M., Pearce B.W., Brandner P.A., Clarke D.B., Moreau D.B. and Xue Y., Steady and unsteady loads acting on a hydrofoil immersed in a turbulent boundary layer. In: $20^{\text {th }}$ Australasian Fluid Mechanics Conference, Perth, Australia, (2016).

18. Humphreys M.D., Measurements of normal-force-coefficient fluctuation on four 9-percentthick airfoils having different locations of maximum thickness. NACA RM $154 B 22$ (1954).

19. Lysak P.D., Capone D.E. and Jonson M.L., Unsteady lift of thick airfoils in turbulent flows. In: Proceedings of ASME IMECE2009-11414 (2009).

20. Stapountzis H. and Graham J.M.R., The unsteady lift on bluff cylindrical bodies in unsteady flow. Aero. Quarterly, 33, (1982), 219-236.

21. Bergami L. and Gaunaa M., ATEFlap aerodynamic model, a dynamic stall model including the effects of trailing edge flap deflection. DTU Risoe-R No 1792, (2012).

22. Oltmann N.-C., Sobota D. and Hoffmann A., Load reduction of wind turbines using trailing edge flaps. In: $4^{\text {th }}$ International Conference on Energy and Environment Research, ICEER 2017, Porto, Portugal, (2017).

23. Li C.F., Xu Y., Zhao X.L. and Xu J.Z., Influence of trailing edge flap on wind turbine using three-dimensional computational fluid dynamics method. In: $6^{\text {th }}$ International Conference on 
Pumps and fans with Compressors and Wind Turbines, IOP Conf. Series: Materials Science and Engineering, 52, (2013), 052005.

24. Bernhammer L.O., Kuik van G.A.M. and Breuker de R., How far is smart rotor research and what steps need to be taken to build a full-scale prototype? In: The Science of Making Torque from Wind, Journal of Physics: Conference Series, 555, (2014), 012008.

25. Plumley C., Leithead W., Jamieson P., Bossanyi E. and Graham J.M.R., Comparison of individual pitch and smart rotor control strategies for load reduction. In: The Science of Making Torque from Wind, Journal of Physics: Conference Series, 524, (2014), 012054.

26. Shan M., Load reducing control for wind turbines: Load estimation and higher level controller tuning based on disturbance spectra and linear models. Dr.-Ing. Dissertation, Uni versitat Kassel, (2017).

27. Njiri J.G. and Soffker D., State-of-the-art in wind turbine control: Trends and challenges. Renewable and Sustainable Energy Reviews, 60, (2016), 377-393. 